\title{
Hemorrhoid through fistula-in-ano: a rare event case
}

\section{Ioannis D. Gkegkes ${ }^{\mathrm{a}, \mathrm{b}}$, Nikolaos Dalavouras ${ }^{\mathrm{a}}$, Apostolos P. Stamatiadis ${ }^{\mathrm{a}}$}

Athens Colorectal Laboratory, Greece; Royal Devon and Exeter NHS Foundation Trust, Exeter, UK

A 40-year-old male presented with 10-day history of anal pain, purulent discharge and burning sensation after defecation. According to the patient's history, no comorbidities were present. On clinical examination of the anal and perianal area, a protruding mass with a maximum diameter of $7 \mathrm{~mm}$ was found at 6 o'clock in the lithotomy position. There was no evidence of local inflammation (Fig. 1).

A 3-dimensional endoanal ultrasound (Hawk type 2050; Bruel and Kjaer Medical, Naerum, Denmark) was performed. Endoanal ultrasound did not reveal any anal/perianal abscess, but only a low posterior fistula-in-ano. The patient was also examined under general anesthesia (EUA). A probe proved the presence of a small internal haemorrhoid inside the fistula (Fig. 2A, B). The entrapped hemorrhoid was freed (Fig. 2C). The canal of the fistula was laid open lengthwise while the previously entrapped hemorrhoid was ligated and resected. Pathology confirmed the histological nature of the resected hemorrhoid. After EUA, all symptoms were resolved.

The incidence of hemorrhoids in the general population ranges between $4.4 \%$ and $36.4 \%$ [1], although it is difficult to estimate their prevalence with precision [2]. Fistula-inano is also a quite frequent condition [3]. This is the first case described in the literature of a hemorrhoid entrapped inside a fistula-in-ano.

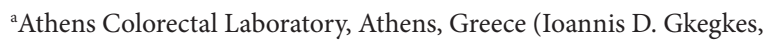
Nikolaos Dalavouras, Apostolos P. Stamatiadis); ${ }^{b}$ Department of Colorectal Surgery, Royal Devon and Exeter NHS Foundation Trust, Exeter, UK (Ioannis D. Gkegkes)

\section{Conflict of Interest: None}

Correspondence to: Ioannis D. Gkegkes, MD, PhD, 17c James House, Residential Village, EX2 5DS, Bovemoors Lane, Exeter, UK, e-mail: ioannisgkegkes@gmail.com

Received 12 December 2019; accepted 17 December 2019 published online 12 February 2020

DOI: https://doi.org/10.20524/aog.2020.0455

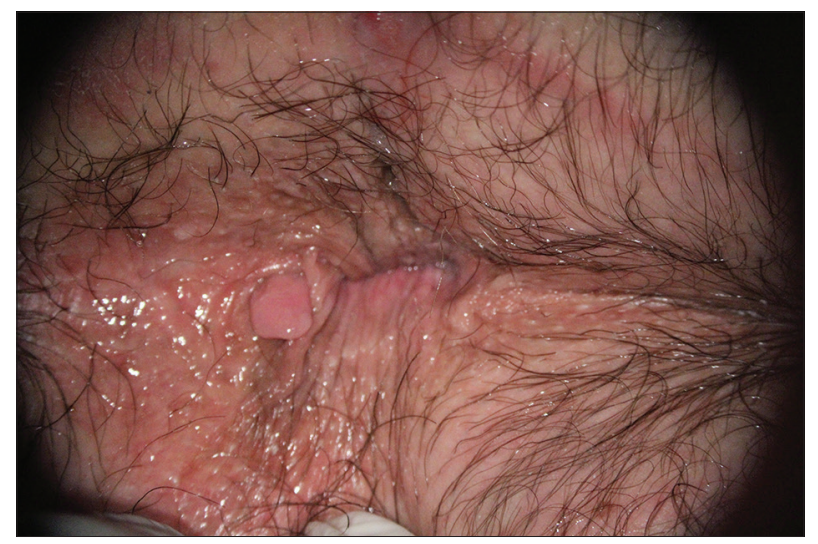

Figure 1 Presence of an area with unusual aspect, at 6 oclock in the lithotomy position
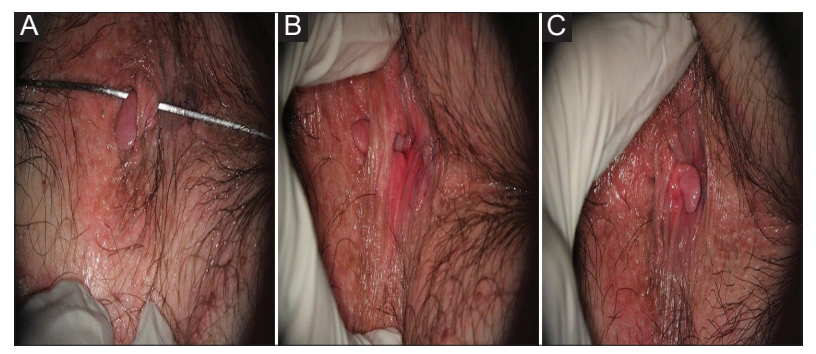

Figure 2 (A) Metallic probe through the canal of the anal fistula. (B) Presence of a small internal hemorrhoid inside the fistula. (C) The entrapped hemorrhoid was freed

\section{References}

1. Loder PB, Kamm MA, Nicholls RJ, Phillips RK. Haemorrhoids: pathology, pathophysiology and aetiology. Br J Surg 1994; 81:946-954.

2. Hardy A, Cohen CR. The acute management of haemorrhoids. Ann $R$ Coll Surg Engl 2014;96:508-511.

3. Hokkanen SR, Boxall N, Khalid JM, Bennett D, Patel H, Prevalence of anal fistula in the United Kingdom. World J Clin Cases 2019;7:1795-1804. 